\title{
Problematic aspects of interpretation of seismic signals induced by detonation of explosives
}

\author{
Józef Pyra ${ }^{*}$, and Michał Twardosz \\ AGH University of Science and Technology, Faculty of Mining and Geoengineering, Cracow, Poland
}

\begin{abstract}
The article presents problems concerning an interpretation of seismic signals registered in the ground and foundations of buildings which are induced by the detonation of explosives. In the course of blasting in opencast mines, harmful effects may occur. The primary impacts which usually occur are as listed, induced vibrations, airblast, acoustic wave and the flyrock. There are technical and technological methods to reduce them, but minimising one can enhance the impact of the other. Furthermore, impacts such as vibration, acoustic wave, and airblast may overlap - the additive effect, which might cause problems with the unambiguous identification and interpretation of the recordings. The paper presents the results of tests carried out on a laboratory scale of the detonation of varying weight explosives samples. Also, examples of seismic signals recorded during field measurements in the vicinity of open-pit mines are presented. Also, examples of seismic signals recorded during field measurements in the vicinity of open-pit mines are presented. These examples confirm doubt as to the applicability of PN-B-02170: 2016-12 to assess the effects of vibrations on the building structures in the event of a significant impact of the airblast.
\end{abstract}

Keywords: shock wave, airblast, ground vibration

\section{Introduction}

Detonation of explosives causes in addition to positive effects (e.g. fragmented rock, broken up foundations, creating a borrow pit for leveling etc.) negative impact in the form of ground and building vibrations, airblast waves, acoustic waves, post-blast fumes, dustiness, and many others depending on the specifics of conducted works using explosives. The blast induced vibrations, airblast wave and acoustic wave can be superimposed because as a physics phenomenon they are categorised as waves that propagate in different media (ground, water, air) with varying velocity. The coexistence of these interactions may cause an intensity change of one impact and reduce the effectiveness of prevention methods of other.

The problematic aspects of the impact of vibrations induced by the detonation of explosive charges on the surroundings is widely discussed around the world. The situation is slightly different when it comes to the issue of the airblast because it is a series of tests that

\footnotetext{
*Corresponding author: pyra@agh.edu.pl
} 
are carried out for military purposes, in which the study of the closest blast zone impact is critical. The research mentioned above is carried out primarily for the protection of vehicles and military facilities. In the case of the use of explosives for civilian purposes (demolition works, blasting works in opencast mines, etc.), they should be designed in such way that they do not cause any damage in the environment. The problem may arise in the situation when the airblast wave affects the construction, and both the Polish standard [1] and the guidelines used in other countries [2, 3, 4] clearly state that the vibrations taken into account for the impact assessment are transmitted through the ground, and they are not caused by an airblast propagation.

Chengqing and Hong [5] state that in the case of detonation of explosives on the surface at small distances the decisive impact is registered from the airblast, at greater distances the effect of ground vibrations starts to outweigh, and at long distance, both phenomena can be now analysed separately.

Gupta, Roy and Singh [6] explains, however, that the vertical axis of vibrations of the rock medium causes oscillation equivalent to the velocity of sound, which causes vibrations in the air at the same frequency as the vertical vibrations of the rock medium, which may result in a disturbance of seismic signals recording. On the other hand, Alcudia [7] and Babcock [8] analysed the possibilities of noise reduction transmitted by air in seismic signals. For this purpose, microphones were used to record sound, so that at a later stage these recordings would serve as a kind of filter, thanks to which it is possible to separate the seismic signal. Moreover, in Faramarzi et al. [9], Kabwe and Wang [10], the issue of the impact of vibrations and airblast, caused by the detonation of explosives, is discussed in the aspect of protecting the environment and people.

The primary objective of the preliminary results of this study was to illustrate problematic aspects of assessment of the signals recorded by the geophones, and which are induced by the detonation on the surface of explosive charges. Incorrect analysis of signals may lead to misinterpretation, especially in the aspect of the impact assessment of vibrations. Another stated problem is the conversion of the airblast in the acoustic wave which should be analysed in different ways using appropriate measurement procedures and analysis.

\section{Methodology}

In order to observe the phenomenon, tests were carried out in field laboratory conditions, during which measurements of ground and building foundations vibrations were performed (sensors were mounted at ground level both inside and outside on the same supporting wall) and changes in air pressure (each test stand was equipped with a microphone). In the course of the research a total of 8 blast series were initiated in which the manner of locating a small mass of explosive charge was changed (about $3 \mathrm{~g}$ ) starting from detonation on the surface, moving on to the suspension of the charge at $0.6 \mathrm{~m}$ height, and ending with a dug in charge at a $0.2 \mathrm{~m}$ depth and covering it with a steel sheet (thickness of $0.06 \mathrm{~m}$ ). The article presents an analysis of the extreme cases, a suspended charge detonation, and an underground detonation.

Due to the fact that the tests were performed in the Republic of Polish, experimental studies were carried out in accordance with the following guidelines:

1. In the field of vibration measurement - Polish standard PN-B-02170:2016-12 Assessment of harmfulness of vibrations transmitted by the ground to buildings [1]. The standard specifies the location and method of mounting sensors for vibration measurements and the minimal technical parameters of vibration sensors. In the assessment using dynamic impacts (SWD I and SWD II scales), seismograms (full waveforms) of horizontal components of vibration should be used, ie with $\mathrm{x}$ and $\mathrm{y}$ (transversal and longitudinal) directions recorded at the measurement point towards the vibration source, at the rigid 
structure node - at the intersection of load-bearing walls - located on the foundation of the building or in a rigid node on the wall of the underground storey at the ground level of the surrounding area. The seismograms should be analysed in one-third bands (tertiary analysis), obtaining in each of the bands the maximum (peak) values of acceleration or velocity of vibration. It means that the assessment of the recordings, according to the SWD scales requirements is to use entire waveforms of recordings of horizontal components. The analysis of the full entries for the $\mathrm{x}$ and $\mathrm{y}$-axes is carried out by filtering the signal with a tertiary filter. The results obtained this way, presented as a histogram of peak particle velocity (PPV) values in a given frequency band, are plotted on the SWD scale assigning the effects corresponding to a given zone. It is an analysis method, based on which, in the case of short-term vibrations (pulses) is made the final assessment. As short-term vibrations, one should understand vibrations, the duration of which in a day does not exceed 3 minutes.

2. In terms of measuring the airblast - there is no guideline in regards to the methodology. The measurements were carried out following the recommendations contained in the [11, 12]. The information provided by the Regulation of the Minister of Economy, Labor and Social Policy of 9 July 2003. On occupational health and safety in the production, intrafactory transport and trading of explosives, including pyrotechnic articles [13], in particular in Annex 2 - Requirements regarding the location of facilities containing explosives classified as class 1 , subclasses 1.1 and 1.5 or class 4.1 can be used to estimate the safety zones when explosives are detonated on the surface.

The UVS 1608 and VIBRALOC equipment from the Swedish company Nitro Consult $\mathrm{AB}$ equipped with broadband ribbon microphones were used to study the vibration intensity and pressure of the airblast. The vibration measurement apparatus meets the requirements of PN-B-02170: 2016-12.

Measuring stands were located as follows (Fig. 1):

Position 1 (st. 1, M1) - the closest to the detonation site - three-component sensor + microphone;

Position 2 (st. 2, M2) - away by $15 \mathrm{~m}$ from st. 1 - three-component sensor + microphone;

Position 3 (st. 3, M3) - on the supporting wall of the building (mounted outside) - threecomponent sensor + microphone;

Position 4 (st. 4, M4) - on the supporting wall of the building (mounted inside) - threecomponent sensor + microphone.

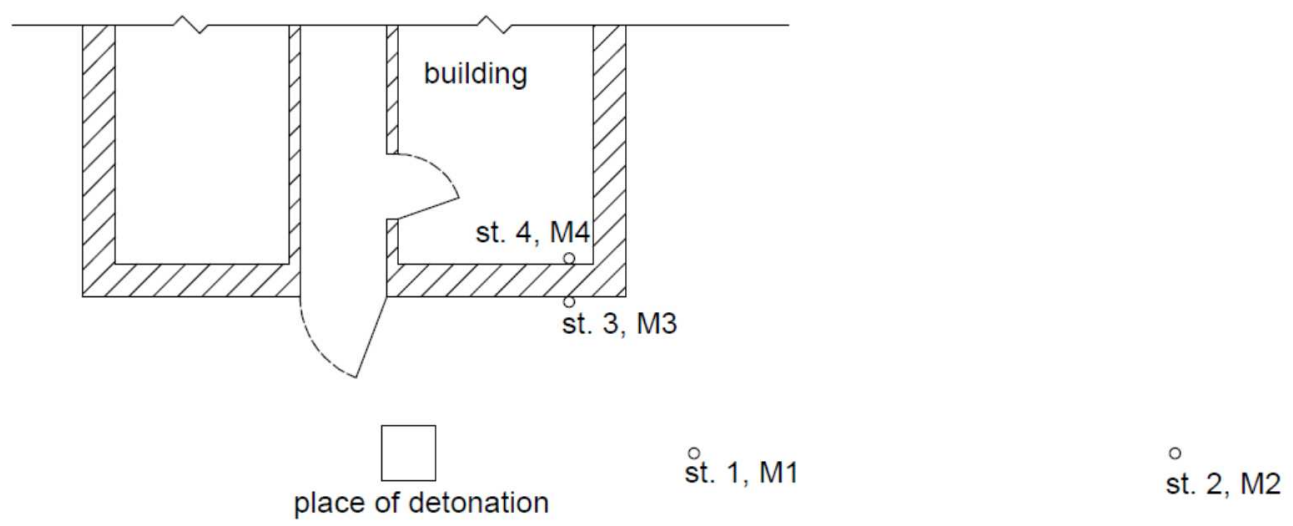

Fig. 1. The sketch of location of measurement stations and explosives detonation. 


\section{Results and discussion}

\subsection{Analysis of the laboratory test results}

Table 1 presents the results of the analysis of full waveforms in the form of peak particle velocity (PPV) of recorded vibrations $\left(u_{z}, u_{x}\right.$ and $\left.u_{y}\right)$ and their corresponding frequency $\left(f_{z}, f_{x}\right.$ and $f_{y}$ ), real vector ( $\left.\mathbf{u}_{\mathbf{z x y}}\right)$ and pressure change corresponding to its frequency.

Table 1. Results of vibration and air shock measurements on individual positions

\begin{tabular}{|c|c|c|c|c|c|c|c|c|c|}
\hline \multirow{2}{*}{$\begin{array}{l}\text { Record } \\
\text { number }\end{array}$} & \multirow[t]{2}{*}{ Position } & \multirow{2}{*}{$\begin{array}{c}\text { Distance, } \\
\text { m }\end{array}$} & \multicolumn{3}{|c|}{$\mathbf{P P V}, \mathrm{m} / \mathrm{s}$} & \multicolumn{3}{|c|}{ Frequency, $\mathrm{Hz}$} & \multirow{2}{*}{\begin{tabular}{|c|} 
Vector, $\mathbf{m} / \mathbf{s}$ \\
$u_{z x y}$ \\
\end{tabular}} \\
\hline & & & $\boldsymbol{u}_{z}$ & $u_{x}$ & $u_{y}$ & $f_{z}$ & $f_{x}$ & $f_{y}$ & \\
\hline \multicolumn{10}{|c|}{ Seria 1} \\
\hline \multirow[t]{4}{*}{048.852} & st. 1 & 6,7 & 0,00235 & 0,00255 & 0,00083 & 360,7 & 380,7 & 476,2 & 0,002831 \\
\hline & M1 & 6,7 & 103,0 & $\mathrm{~Pa}$ & & 109,0 & $\mathrm{~Hz}$ & & \\
\hline & st. 2 & 21,5 & 0,00053 & 0,00045 & 0,0001 & 269,8 & 126,6 & 125,0 & 0,000693 \\
\hline & M2 & 21,5 & 87,2 & $\mathrm{~Pa}$ & & 21,8 & $\mathrm{~Hz}$ & & \\
\hline \multirow[t]{2}{*}{723.1958} & st. 3 & 4,8 & 0,0009 & 0,00128 & 0,00105 & 352,0 & 351,0 & 332,0 & 0,001455 \\
\hline & M3 & 4,8 & 343,9 & $\mathrm{~Pa}$ & & 4,0 & $\mathrm{~Hz}$ & & \\
\hline \multirow[t]{2}{*}{722.0936} & st. 4 & 5,0 & 0,00104 & 0,00163 & 0,00182 & 216,0 & 191,0 & 362,0 & 0,00188 \\
\hline & M4 & 5,0 & 5,9 & $\mathrm{~Pa}$ & & 146 & $\mathrm{~Hz}$ & & \\
\hline \multicolumn{10}{|c|}{ Seria 2} \\
\hline \multirow[t]{4}{*}{048.853} & st. 1 & 7,3 & 0,00055 & 0,00155 & 0,00045 & 66,7 & 89,2 & 82,0 & 0,001614 \\
\hline & M1 & 7,3 & 23,2 & $\mathrm{~Pa}$ & & 155,0 & $\mathrm{~Hz}$ & & \\
\hline & st. 2 & 22,2 & 0,00045 & 0,00008 & 0,00015 & 12,3 & 33,8 & 78,1 & 0,000451 \\
\hline & M2 & 22,2 & 1,2 & $\mathrm{~Pa}$ & & 75,8 & $\mathrm{~Hz}$ & & \\
\hline \multirow[t]{2}{*}{723.1959} & st. 3 & 6,6 & 0,00015 & 0,00013 & 0,00011 & 58,6 & 71,2 & 24,9 & 0,000166 \\
\hline & M3 & 6,6 & 11,8 & $\mathrm{~Pa}$ & & 4,0 & $\mathrm{~Hz}$ & & \\
\hline \multirow[t]{2}{*}{722.0937} & st. 4 & 6,8 & 0,00017 & 0,00016 & 0,00023 & 107,0 & 55,4 & 3,8 & 0,000256 \\
\hline & M4 & 6,8 & 1,1 & $\mathrm{~Pa}$ & & 0,1 & $\mathrm{~Hz}$ & & \\
\hline
\end{tabular}

In order to outline the problems as mentioned earlier, Figures 2-5 present examples of vibration recordings at the horizontal axis (x) and airblast. Also, the amplitudes of the Fourier transform were determined. A full analysis was analogously performed for all components.

Figure 2 presents the recording of ground vibrations at position 1 and 2 (difference of the distance between them was $15 \mathrm{~m}$ ) the horizontal component directed perpendicular to the detonation site of the explosive charge which was fired at $0.6 \mathrm{~m}$ height, and airblast pressure record at the same positions (the microphone was placed directly above the ground position at the height of $0.6 \mathrm{~m}$ ). 

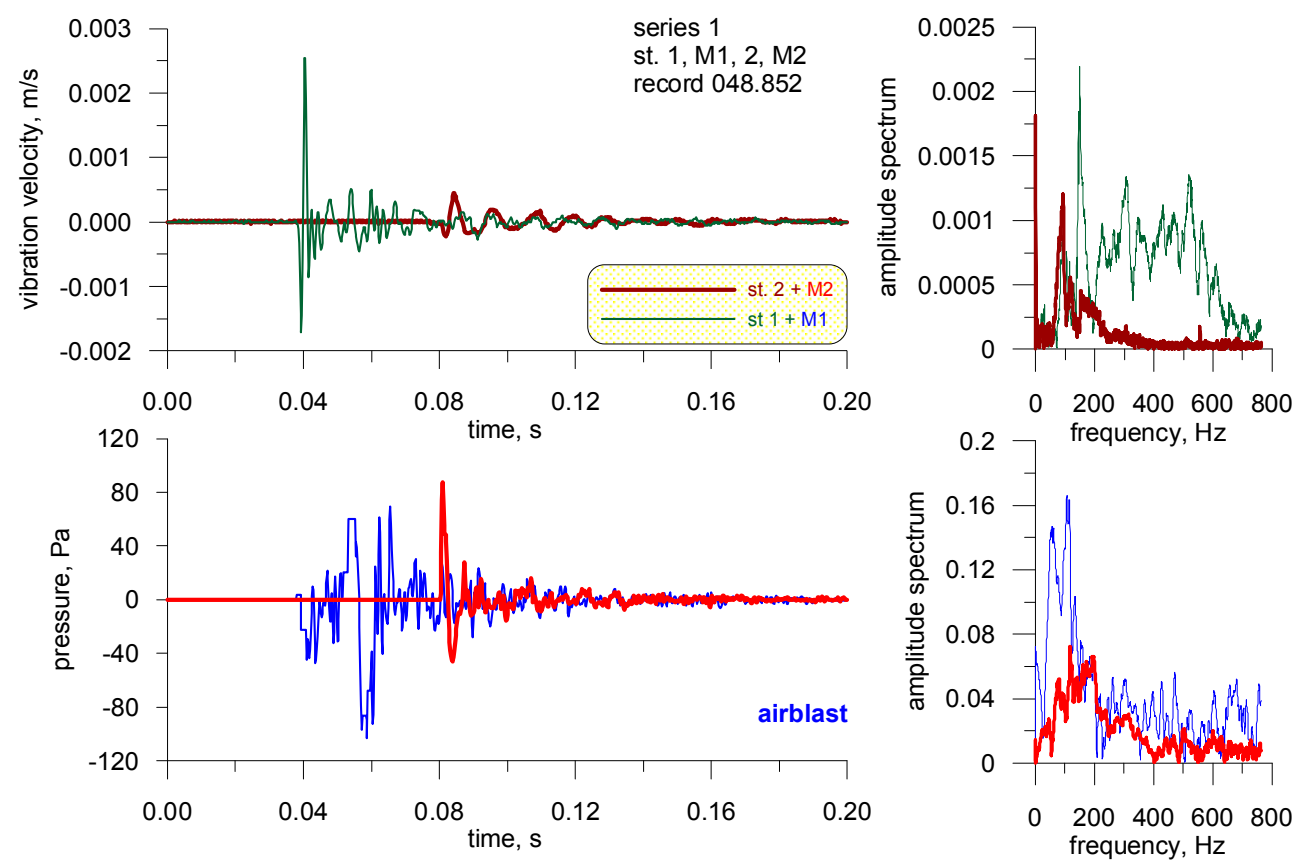

Fig. 2. Recording of ground vibrations and airblast pressure along with the amplitude spectrum (FFT) - series 1 .

Registration at ground posts begun when the pressure changes reached the microphones, which probably indicates that the vibrations had been excited by air movement. When determining the difference between the entry time among microphones, the propagation velocity of the pressure change was calculated, which amounted to approx. $375 \mathrm{~m} / \mathrm{s}$ (the air temperature during the measurements was about $15^{\circ} \mathrm{C}$ ) which indicates that it was an airblast. Microphones, moreover, registered acoustic waves, which is confirmed by the frequency structure. During this test, vibration sensors and microphones were installed in the building object on the outer and inner side of the supporting (load bearing) wall at the ground level (the wall formed a mirror reflection for mounted sensors). The records of this study are shown in Figure 3.

Analyzing Fig. 3, it can be noticed that locking the microphone inside the facility (all doors and windows in the building were closed) resulted in a complete attenuation of the airblast. In the frequency structure of the recording from the microphone set outside, higher frequencies, distinctive for the acoustic wave, can be observed. What might be considered surprising, however, is the fact that the vibration sensors registered practically the same, except for the outside sensor which recorded a higher intensity in the first phase of vibration and the inside sensor in the second phase. The frequency structure is similar, the higher frequencies in the range from $200 \mathrm{~Hz}$ to $300 \mathrm{~Hz}$ dominate, which is not characteristic of the building object's natural vibrations. As a result of comparison Figure 2 and 3, it can be observed that the vibration sensors installed in the ground respond in an utterly different way compared to the sensors mounted on a building. This situation was repeated each time the explosive charge was placed in this specific manner. The other components of the sensor (vertical and transversal) behaved similarly, with the difference that the recording on the vertical axis is much longer than on the horizontal axes for stations 3 and 4 . 

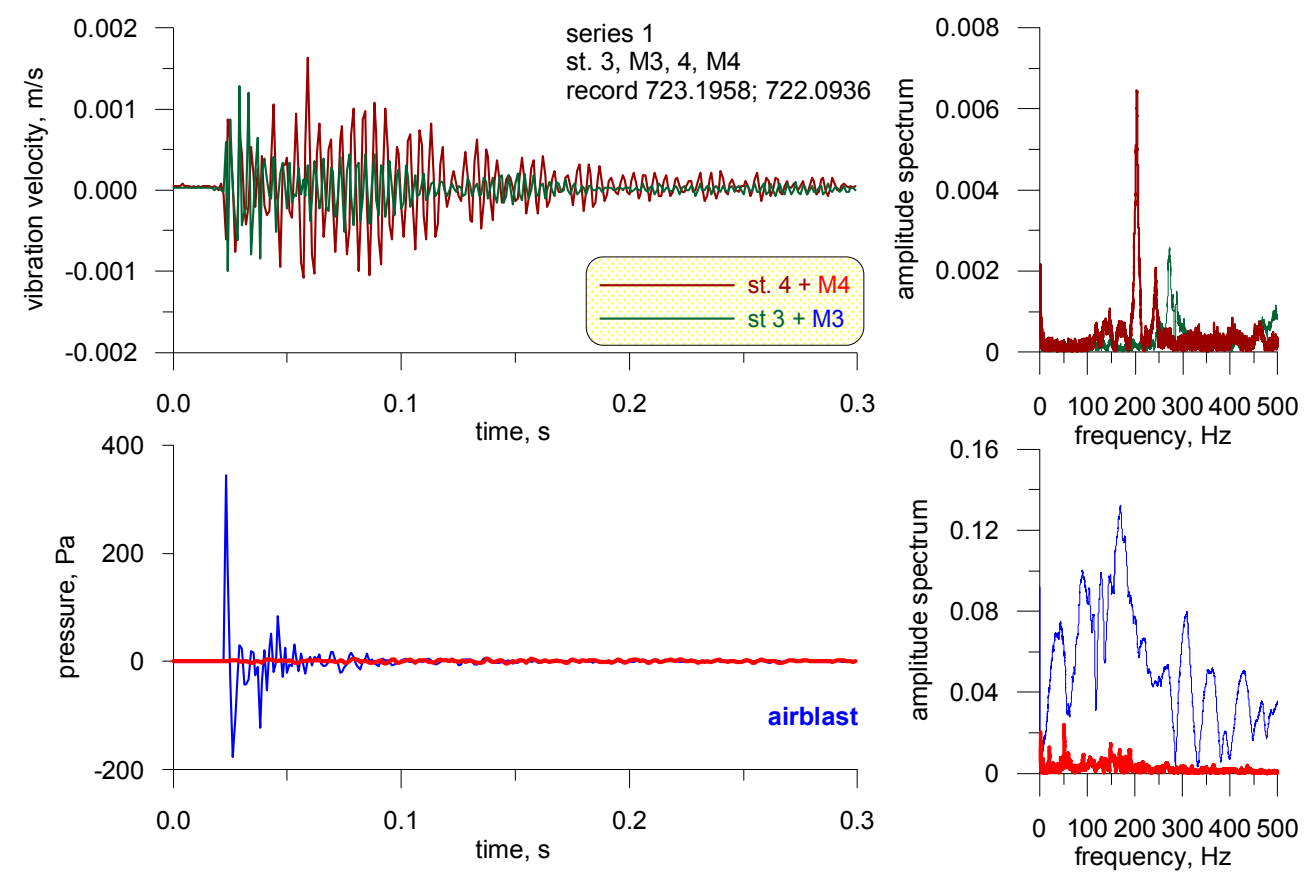

Fig. 3. Recording of structure vibrations and airblast pressure along with the amplitude spectrum (FFT) - series 1.

The next group of measurements was measurements carried out with buried and additionally covered with steel plate explosives charge. The results of those studies are shown in Fig. 4 for positions 1 and 2, as well as in Fig. 5 for test stands 3 and 4. When conducting the analysis of Fig. 4, it can be noticed that the records are different in comparison to the records presented in Figures 2 and 3. The shock wave has been completely suppressed. As a result of the detonation, the steel plate was slightly raised, which caused a recording from the fall in the second part of the entry (about $300 \mathrm{~ms}$ ) at test station 1. At position two it is significantly reduced. By determining, in the same way as in the first series of tests, differences in the time of entry between microphones, the propagation velocity of the pressure change was calculated, which amounted to approx. $342 \mathrm{~m} / \mathrm{s}$ (air temperature during measurements was about $15^{\circ} \mathrm{C}$ ), which proves that it was an acoustic wave.

The excited vibrations in the ground were suppressed at the transition to the building, where vibrations were recorded, which slightly exceeded the trigger threshold $(0.25 \mathrm{~mm} / \mathrm{s})$. It is also confirmed by the frequency structure, where the entire spectrum of frequencies ranges from $1 \mathrm{~Hz}$ to $500 \mathrm{~Hz}$ (noise). 

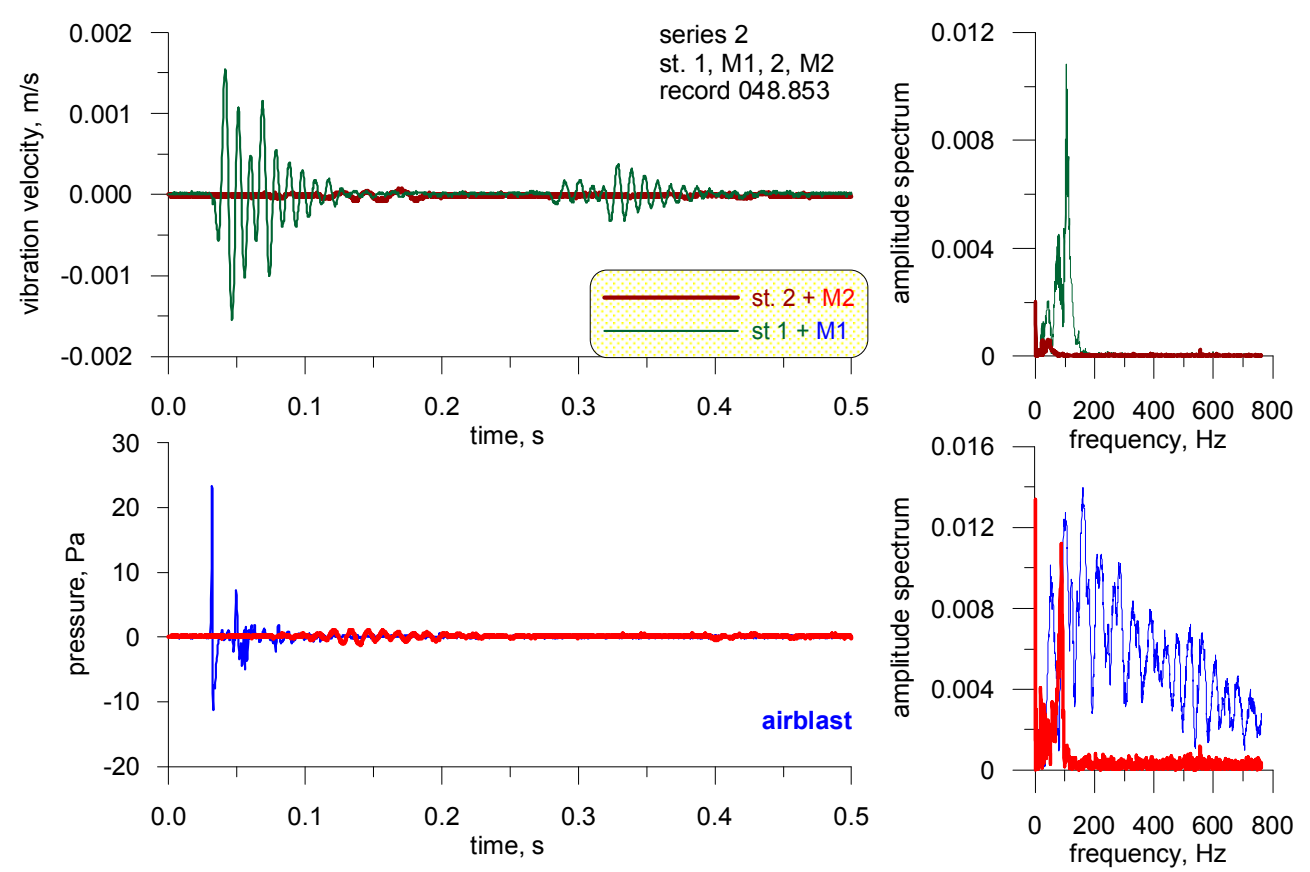

Fig. 4. Recording of ground vibrations and airblast pressure along with the amplitude spectrum (FFT) - series 2 .

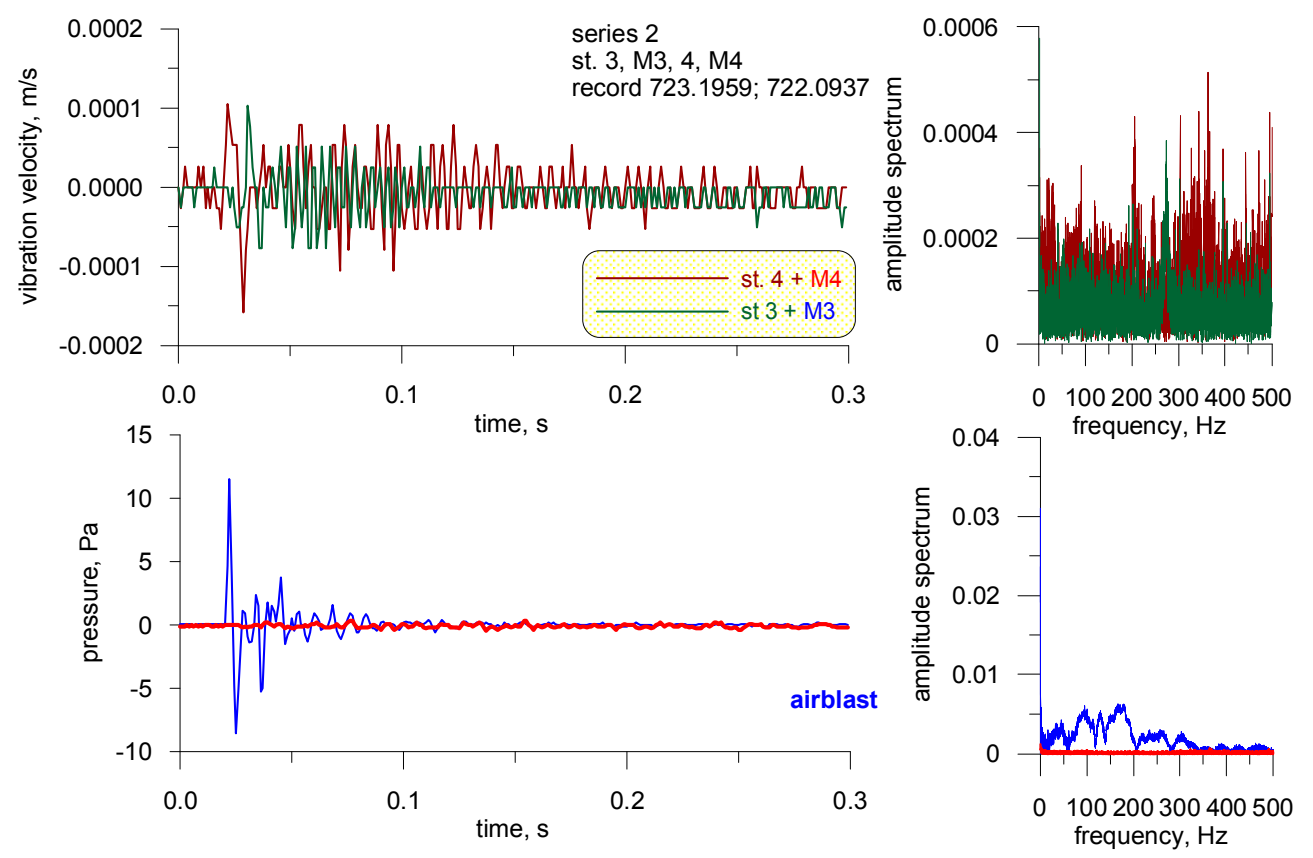

Fig. 5. Recording of structure vibrations and airblast pressure along with the amplitude spectrum (FFT) - series 2. 


\subsection{Analysis of selected results of field research}

In the course of field measurements of ground's and building's vibrations in the vicinity of the chosen open-pit mine, where blasting works were carried out at the top floor of production levels, air shock waves were also recorded. Production blasting was carried out using the long hole method. Measurement positions were placed in the direction to the nearest buildings. Presented vibration and airblast registrations from the selected test stands, as shown in Fig. 6, were moved away from the blasting site, respectively: st. 21 and M21 - 630 m, st. 25 and 25 '- $1147 \mathrm{~m}$.
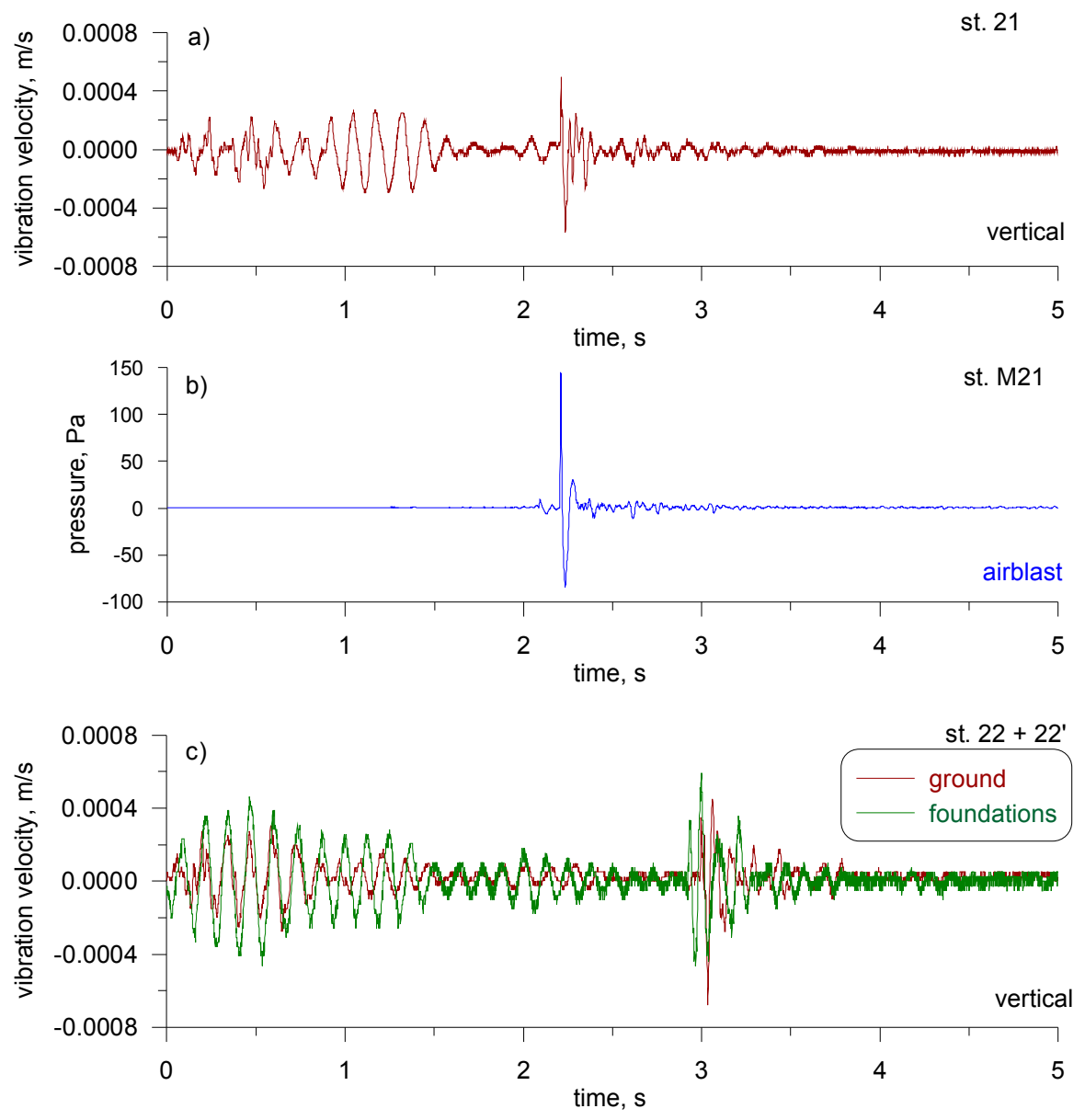

Fig. 6. Recordings of: a) ground vibrations; b) airblast; c) ground and building vibrations.

Vibration analysis of the records registered in the position 21 indicates the impact of airblast on vibration sensors, thanks to the installed microphone. Records from measurement stands 22 and 22 ' also clearly display previously mentioned impact, which caused higher intensity vibrations on the construction in comparison to vibrations transmitted by the ground. In order to correctly perform impact assessment for protected structures, moreover, do it in accordance with the requirements of the standard [1], it is necessary to eliminate from the signal the disruption (interference) caused by the airblast. 


\section{Conclusions}

The article presents examples of signal measurements induced by the detonation of small charges of explosives placed in various ways, studies related to the distribution of selected physic fields. The perceived hazard is caused by the short-term and high-energy shock waves - acoustic, airblast (gust) and seismic. Based on the research and analyses carried out, it can be concluded that:

1. Doubts were confirmed as to the applicability of the PN-B-02170: 2016-12 standard, which concerns assessment of the vibration impact on buildings which are transmitted by the ground, and not by air (pressure change). The statement of this fact was possible thanks to the simultaneous measurement of vibrations and airblast.

2. In order to apply the standard [1] to assess the impact of vibrations on buildings, air-borne interference must be eliminated from the recordings.

3. There is still a doubt as to whether the recorded impact consisting of airblast and acoustic wave by the vibration sensors was an impact on the object and the substrate, or whether it was only affecting the sensor itself.

Research will be continued in order to develop a measurement and analytical methodology, so as not to misinterpret the recorded vibrations, and thus to incorrectly evaluate the impact on protected structures.

\section{References}

1. PN-B-02170:2016-12-Assessment of the impact of vibrations transmitted by the ground on buildings (in Polish)

2. DIN 4015-1:2001-06 Vibrations in buildings - Part 1: Prediction of vibration parameters

3. DIN 4150-3:2016-12 Vibrations in buildings - Part 3: Effects on structures

4. Eurocode 8: Design of structures for earthquake resistance - Part 1: General rules, seismic actions and rules for buildings

5. W. Chengqing, H. Hong, International Journal of Impact Engineering 34, 556-572 (2007) doi: 10.1016/j.ijimpeng.2005.11.003

6. R. N. Gupta, P.P. Roy, B. Singh, International Journals of Mining and Geological Engineering 6, 15-26 (1988) doi: 10.1007/BF00881024

7. A. D. Alcudia, University of Calgary (2009) doi: 10.11575/PRISM/15296

8. N.M. Babcock, Microphone suppression of air-noise on geophones, (M. Sc. thesis, Faculty of the Department of Earth and Atmospheric Sciences University of Houston, 2012)

9. F. Faramarzi, M. A. Ebrahimi Farsangi, H. Mansouri, International Journal of Mining Science and Technology 24 (5) 663-669 (2014) doi: 10.1016/j.ijmst.2014.07.006

10. E. Kabwe, Y. Wang, Geomaterials 6, 28-38 (2016) doi: 10.4236/gm.2016.61003

11. V. J. Stachura, D. E. Siskind, A.J. Engler Airblast Instrumentation and Measurement Technique for Surface Mine Blast. U. S. Bureau of Mines, Report of Investigations 8508 (2000)

12. J. Winzer, A. Sołtys, J. Pyra, The impact of in use of blasting works on the environment, AGH University of Science and Technology Press, Krakow (2016) (in Polish)

13. Regulation of the Minister of Labour and Social Policy of 9 July 2003 on health and safety during the production, in-house transport and circulation of explosives, including pyrotechnic articles., Journal of Laws of 2003, no. 163, item 1577 (in Polish) 